\title{
DADOS DE ESCOLARIZAÇÃO DOS ESTUDANTES DE LETRAS E DE PEDAGOGIA: EM BUSCA DOS SABERES DE FORMAÇÃO BÁSICA DOS FUTUROS PROFESSORES
}

\author{
DATA OF SCHOOLING OF STUDENTS OF LETRAS AND PEDAGOGY: SEEKING BASIC TRAINING \\ KNOWLEDGE OF FORTHCOMING TEACHERS
}

\author{
Marcelo Macedo Corrêa e Castro* \\ Universidade Federal do Rio de Janeiro, BR
}

RESUMO: O presente artigo apresenta e discute dados de escolarização básica dos estudantes matriculados nos cursos de Letras, Português-Literaturas, e Pedagogia na UFRJ no ano de 2010. Os dados, a serem futuramente relacionados a outros grupos de informação, apontam para um primeiro perfil dos referidos estudantes, situando-os, em sua maioria, como oriundos de processos de escolarização básica de qualidade aquém da desejável para o início de sua graduação, traço que se confirma parcialmente pelos resultados que obtêm nos exames de ingresso na Universidade.

PALAVRAS-CHAVE: ensino da escrita; saberes docentes; formação de professores.

ABSTRACT: In this paper I present and discuss data concerning the basic schooling of students of Letras (Portuguese/Literature) , and Pedagogy from UFRJ in 2010. These data, which shall be connected to other data sources in the future, show a preliminary profile of the above mentioned students that situate them under the level of basic education desirable for an undergraduate student. This profile is partially confirmed when related to their results in the university entrance examination process.

KEYWORDS: teaching of writing; teacher's knowledge; teacher education.

\section{INTRODUÇÃO}

Desde 2010, desenvolvemos o projeto Saberes docentes e formação de professores para o ensino da escrita ${ }^{l}$, no qual estão previstos inicialmente dois focos de investigação: (1) a identificação do perfil socioeconômicocultural dos estudantes matriculados nos cursos de Pedagogia e de Letras, Português-Literaturas, da UFRJ, com ênfase na sua formação básica, e (2) a análise dos currículos dos cursos em questão, com base nas propostas oficiais, nos depoimentos dos sujeitos envolvidos e na bibliografia pertinente.

No primeiro ano de desenvolvimento do projeto em que se insere o presente estudo, dedicamos nossa atenção aos saberes docentes. Com relação a esse aspecto, nosso referencial deriva fundamentalmente das leituras que fizemos de Lessard e Tardif (2008), Lelis (2001), Tardif (2007), Nóvoa (2008), e Pimenta (2008). Em trabalho apresentado no I Seminário Internacional de Ensino de Língua Portuguesa, realizado em 2011, na Universidade Federal de Uberlândia (CASTRO, 2011), sintetizamos nossas leituras sobre saberes docentes por meio da seguinte lista de aspectos em comum:

1. A formação de professores envolve saberes de naturezas diversas e obtidos por meio de processos variados.

2. Parte desses saberes se constrói por meio da experiência fora das agências de formação, parte vem dessas agências e parte vem da prática profissional, sendo possível subcategorizálos de muitas formas e com inúmeros critérios.

\footnotetext{
*mar.castro@globo.com.

${ }^{1}$ Projeto coordenado pelo autor do artigo e desenvolvido em grupo do qual fazem parte a Professora Rejane Almeida, o Profesor Luiz Otávio Langlois e as estudantes de graduação Camila Barbalho e Maria Elisa Vieira. O projeto está vinculado ao Laboratório de Estudos de Leitura, Escrita e Educação - LEDUC - da Faculdade de Educação da UFRJ.
} 
3. A hierarquização e, mais do que isso, a articulação desses grupos de saberes em termos de sua importância para a formação dos professores constitui um desafio que ainda estamos longe de ter vencido.

4. A necessária articulação entre saberes e, sobretudo, entre teoria e prática ocorre de forma fluida, em uma dinâmica razoavelmente imprevisível e, portanto, incontrolável, e não de maneira linear e racional.

5. Ainda que lançando mão de diferentes denominações, a maioria dos pesquisadores destaca o papel primordial que saberes identificáveis como habitus ${ }^{2}$, tal e qual definido por Bourdieu (1972, p.178-179, apud PERRENOUD, 2002, p.147), desempenham na formação e, particularmente, na ação dos professores.

No ano atual, temos concentrado nossas leituras em estudos que tratem mais especificamente das questões do sentido da escrita e da formação de professores para o seu ensino. Autores como Barthes (1997), Britto (1997), Geraldi (1997), Kramer (2000), Castro (2008), e Leta (2005) têm servido de referência às nossas reflexões. Embora ainda em curso, o atual movimento já nos levou a produzir uma escolha básica sob o ponto de vista conceitual. Trata-se de uma opção por um ensino da escrita que, superando a mera instrumentalização para a confecção de produtos escritos supostamente necessários para a vida escolar e, posteriormente, a social, signifique um processo de constituição dos sujeitos e, desta forma, contribua fundamentalmente para a sua humanização em sentido pleno.

A definição das linhas básicas do projeto deriva da nossa convicção de que a Universidade tem investido abaixo do que deveria na formação inicial de professores. Seja por ter atravessado quase duas décadas de desmonte do quadro docente (de fins dos anos 1980 até meados dos anos 2000), o que enfraqueceu ou mesmo impossibilitou esforços de renovação em todas as frentes de atuação, seja por ter se voltado mais para ações da chamada formação continuada, cuja demanda por parte das políticas de governo foi intensa no período mencionado, seja ainda por outras razões, é fato que, a despeito de projetos e estudos isolados de grupos e pesquisadores, a UFRJ não teve como prioridade valorizar seus cursos de formação de professores.

Por conta dessa baixa valorização, ficamos limitados a reformas curriculares que, de um lado, respondem, às vezes tardiamente, a movimentos nacionais mais amplos e, de outro, resultam de determinações legais. Como decorrência desse quadro, os cursos aqui referidos vivem atualmente um período de implantação de currículos recém reformados, sem que se tenha clareza sobre diversos aspectos fundamentais para o desenvolvimento desse processo.

\section{METODOLOGIA}

Para contribuir com elementos que permitam a superação dessas lacunas, destacamos um primeiro aspecto básico para a implantação de um novo currículo: o conhecimento acerca dos estudantes matriculados no curso. Em nosso caso, escolhemos começar por dados do questionário socioeconômico-cultural que os estudantes preenchem durante o processo de ingresso na UFRJ. Trata-se de um instrumento com 41 questões ${ }^{3}$, que classificamos em quatro diferentes grupos de dados: (1) escolarização. (2) escolha do curso; (3) condições socioeconômicas do estudante e da sua família; e (4) acesso a bens culturais.

Trata-se de um estudo metodologicamente desenvolvido em duas etapas. Na primeira, de caráter quantitativo, ocupamo-nos da mera tabulação dos indicadores, produzindo gráficos e tabelas, com os respectivos percentuais de ocorrência das respostas a todas as 41 questões do instrumento aplicado pela

\footnotetext{
2 "um sistema de disposições duradouras e transponíveis que, ao integrar todas as experiências passadas, funciona a cada momento como uma matriz de percepções, de apreciações e de ações, tornando possível a realização de tarefas infinitamente diferenciadas, graças às transferências analógicas de esquemas que permitem resolver os problemas da mesma forma”.

s A partir da entrada da UFRJ no SISU, que se deu após o período focalizado em nosso estudo, o questionário foi modificado.
} 
UFRJ. A segunda consiste de uma análise de tais resultados, em correlação com o objetivo maior de identificar no perfil encontrado elementos que permitam sugerir intervenções teórico-práticas nos cursos de formação de professores que estamos investigando. Finda esta segunda etapa, temos a intenção de promover cruzamentos de dados diversos. Isto, todavia, ainda está por ser definido e dependerá da apropriação dos grupos de dados 2,3 e 4.

Neste artigo, apresentarei um estudo dos dados de escolarização, como primeiro passo com vistas à construção de um perfil que considere o conjunto das informações e de suas múltiplas e complexas relações. $\mathrm{O}$ destaque do grupo de dados referentes à formação básica dos estudantes permite incluir no contexto de nossas ações como formadores um dos saberes docentes identificados por Tardif (2007, p.63): os "saberes provenientes da formação escolar anterior".

\section{APRESENTAÇÃO DOS DADOS}

No desenvolvimento dos cursos em questão, não há sinal algum de que as práticas sejam definidas, alimentadas e avaliadas com o suporte de dados da formação anterior dos estudantes. Há consensos, "lendas", "mitos" sobre a escolarização dos estudantes, mas não há estudos sistemáticos sobre tal etapa e, portanto, não se acumulou historicamente qualquer prática de trabalhar com os dados relativos a ela. Entendemos que essa falha precisa ser superada por uma nova perspectiva de trabalho e, nesse sentido, iniciamos nosso estudo sobre os currículos tentando identificar quem são os discentes que atuam em sua concretização.

Passamos, então, a apresentar o grupo de dados que analisamos, composto pelas questões de 1 a 8 do questionário. O universo de respondentes se compõe dos 300 estudantes matriculados em Letras (150) e Pedagogia (150) em 2010. Os dados foram fornecidos pela Comissão Executiva dos Concursos de Acesso aos Cursos de Graduação da UFRJ. Esta primeira apresentação terá um caráter essencialmente descritivo. Na parte seguinte do artigo (item 4), abordaremos os dados analiticamente.

Quadro 1 - Local em que fez a maior parte do ensino médio:

\begin{tabular}{l|c|c|c|c}
\hline \hline $\begin{array}{c}\text { Questão 1: Local onde fez a maior parte } \\
\text { do ensino médio: }\end{array}$ & Letras & \% & Pedagogia & $\%$ \\
\hline Em outra cidade do Estado do RJ & 38 & 25,4 & 28 & 18,7 \\
\hline Na cidade do Rio de Janeiro & 101 & 67,4 & 115 & 76,7 \\
\hline Na Região Sudeste (exceto RJ) & 5 & 3,3 & 4 & 2,7 \\
\hline Nas regiões Norte e Nordeste & 2 & 1,3 & 0 & 0 \\
\hline Não Respondeu & 4 & 2,6 & 3 & 2,0 \\
\hline Total & $\mathbf{1 5 0}$ & $\mathbf{1 0 0 , 0}$ & $\mathbf{1 5 0}$ & $\mathbf{1 0 0 , 0}$ \\
\hline \hline
\end{tabular}

Os respondentes, em sua ampla maioria, estudaram na cidade do Rio de Janeiro durante o ensino médio: $67,4 \%$ dos de Letras e $76,7 \%$ dos de Pedagogia. Mais ampla ainda se mostra a maioria com relação ao Estado do Rio de Janeiro: 92,8\% e 95,4\%, respectivamente. Adicionalmente, destacamos que os estudantes oriundos de outros municípios se concentram em locais a menos de $100 \mathrm{~km}$ de distância da cidade do Rio de Janeiro $^{4}$, na região metropolitana. Apenas cerca de $3 \%$ vêm de outra cidade da Região Sudeste. E somente dois declararam ter estudado em outras regiões do país.

4 Lista completa: Barra Mansa, Belford Roxo, Duque de Caxias, Itaboraí, Macaé, Magé, Maricá. Mesquita, Petrópolis, Nilópolis, Niterói, Nova Iguaçu, São Gonçalo, São João de Meriti, São Pedro da Aldeia e Volta Redonda 
Quadro 2 - Tipo de escola em que cursou o ensino fundamental:

\begin{tabular}{l|c|c|c|c}
\hline \hline \multicolumn{1}{c|}{$\begin{array}{c}\text { Questão 2: Você frequentou o ensino } \\
\text { fundamental: }\end{array}$} & Letras & \% & Pedagogia & \% \\
\hline Maior parte em escola particular & 14 & 9,3 & 12 & 8,0 \\
\hline Maior parte em escola pública & 17 & 11,3 & 16 & 10,7 \\
\hline Não Respondeu & 4 & 2,6 & 3 & 2,0 \\
\hline Todo em escola particular & 74 & 49,4 & 53 & 35,3 \\
\hline Todo em escola pública & 41 & 27,4 & 66 & 44,0 \\
\hline Total & $\mathbf{1 5 0}$ & $\mathbf{1 0 0 , 0}$ & $\mathbf{1 5 0}$ & $\mathbf{1 0 0 , 0}$ \\
\hline \hline
\end{tabular}

A maioria dos estudantes de Pedagogia, 44\%, fez todo o ensino fundamental em escola pública. O percentual sobe para $55 \%$ quando acrescido dos $11 \%$ que cursaram a maior parte desse nível em escola pública. A relação se inverte, porém, no caso dos estudantes de Letras: 49,4\%, praticamente a metade, cursaram todo o ensino fundamental em escolas particulares. Chama atenção também o fato de que $35 \%$ dos matriculados em Pedagogia tenham feito todo o ensino fundamental em escola particular.

Para maior aprofundamento da questão, seria necessário investigar o perfil das instituições e os motivos da sua escolha por parte das famílias. Embora não tenhamos em nosso grupo formulado hipóteses para explicar essa distribuição, ela parece confirmar um traço que tem caracterizado a constituição e a ocupação da malha de escolas no Estado do Rio de Janeiro, especialmente na capital. Com a perda de valor da escola pública, as camadas populares veem nas instituições privadas uma saída para a garantia de uma escolarização mais segura e propiciadora de melhores oportunidades de colocação social. Há uma proliferação de escolas privadas de custo acessível às classes subalternas que poderia explicar em parte o Quadro 2.

Para fins de síntese, não obstante as observações aqui apresentadas, registramos que os estudantes de Letras, em sua maioria, cursaram o ensino fundamental todo $(49,4 \%)$ ou na maior parte $(9,3 \%)$ em escolas particulares, ao passo que os de Pedagogia cursaram esse nível todo $(44,0 \%)$ ou na maior parte $(10,7 \%)$ em escolas públicas.

Quadro 3 - Modalidade de ensino médio cursado:

\begin{tabular}{l|c|c|c|c}
\hline \hline Questão 3: Que curso de ensino médio você & $\begin{array}{c}\text { Total } \\
\text { fez? }\end{array}$ & $\mathbf{\%}$ & $\begin{array}{c}\text { Total } \\
\text { Pedagogia }\end{array}$ & \% \\
\hline Atual curso de ensino médio & 99 & 66 & 69 & 46,0 \\
\hline $\begin{array}{l}\text { Magistério do Ensino Fundamental (Curso } \\
\text { Normal) }\end{array}$ & 17 & 11,3 & 50 & 33,3 \\
\hline Não Respondeu & 5 & 3,4 & 3 & 2,0 \\
\hline Outro & 3 & 2 & 2 & 1,3 \\
\hline Supletivo & 4 & 2,6 & 9 & 6,0 \\
\hline Técnico & 22 & 14,7 & 17 & 11,3 \\
\hline Total & $\mathbf{1 5 0}$ & $\mathbf{1 0 0 , 0}$ & $\mathbf{1 5 0}$ & $\mathbf{1 0 0 , 0}$ \\
\hline \hline
\end{tabular}

Os maiores percentuais ficam por conta do ensino médio regular: 66\% (Letras) e 46\% (Pedagogia). Apenas $2,6 \%$ e $6 \%$, respectivamente, cursaram a modalidade Supletivo. Já os percentuais referentes àqueles que fizeram ensino técnico merecem alguma atenção: $14,7 \%$ e 11,3\%. O destaque, contudo, fica por conta do fato de que um terço exato (50) dos estudantes de Pedagogia e 11,3\% dos de Letras cursaram a modalidade Magistério do Ensino Fundamental, vulgarmente conhecida como Curso Normal, ocorrência que também precisa ser investigada mais detalhadamente, com vistas a se identificar até que ponto se trata de uma busca efetiva de formação para o magistério. 
Quadro 4 - Tipo de escola em que cursou o ensino médio:

\begin{tabular}{l|c|c|c|c}
\hline \hline Questão 4: Você frequentou o ensino médio: & Letras & $\mathbf{\%}$ & Pedagogia & $\mathbf{\%}$ \\
\hline Maior parte em escola particular & 9 & 6 & 2 & 1,3 \\
\hline Maior parte em escola pública & 1 & 0,5 & 6 & 4 \\
\hline Não Respondeu & 5 & 3,4 & 5 & 3,3 \\
\hline Todo em escola particular & 67 & 44,7 & 45 & 30 \\
\hline Todo em escola pública & 68 & 45,4 & 92 & 61,3 \\
\hline Total & $\mathbf{1 5 0}$ & $\mathbf{1 0 0 , 0}$ & $\mathbf{1 5 0}$ & $\mathbf{1 0 0}$ \\
\hline \hline
\end{tabular}

Há alguma semelhança com o Quadro 2, relativo ao ensino fundamental, na medida em que os estudantes de Letras continuam a apresentar percentuais mais altos que os de Pedagogia no que se refere à sua relação com as escolas particulares. No caso do ensino médio, porém, em ambos os grupos, os maiores percentuais ficam com a opção "Todo em escola pública": 45.4\% dos de Letras e 61,3\% dos de Pedagogia. Os dois grupos registram aumentos expressivos em relação à mesma opção no caso do ensino fundamental: 18 e 17,3 pontos percentuais. Ressalve-se, no caso dos estudantes de Letras, que, somadas as opções "todo e maior parte", as escolas públicas apresentam total de $45,9 \%$, enquanto as particulares somam $50,7 \%$. Não obstante a ressalva, o expressivo aumento de estudantes nas escolas públicas em relação ao ensino fundamental também carece de investigação mais detida e talvez possa ter alguma relação com o caso da opção pela modalidade Normal, cuja oferta, como já salientamos, é mais expressiva na rede pública estadual.

Quadro 5 - Turno em que estudou no ensino médio:

\begin{tabular}{l|c|c|c|c}
\hline \hline \multicolumn{1}{c|}{$\begin{array}{c}\text { Questão 5: Em que turno você cursou a maior } \\
\text { parte do ensino médio? }\end{array}$} & Letras & $\mathbf{\%}$ & Pedagogia & \% \\
\hline Integral (manhã e tarde) & 15 & 10 & 14 & 9,3 \\
\hline Manhã & 103 & 68,7 & 94 & 62,7 \\
\hline Não Respondeu & 4 & 2,6 & 3 & 2 \\
\hline Noite & 7 & 4,7 & 23 & 15,3 \\
\hline Tarde & 21 & 14 & 16 & 10,7 \\
\hline Total & $\mathbf{1 5 0}$ & $\mathbf{1 0 0 , 0}$ & $\mathbf{1 5 0}$ & $\mathbf{1 0 0}$ \\
\hline \hline
\end{tabular}

A maioria estudou de manhã: 68,7\% (Letras) e 62,7\% (Pedagogia). Somados aos 14\% e 16\% que estudaram à tarde, fica estabelecida uma clara predominância dos turnos diurnos em relação ao noturno: enquanto as opções manhã e tarde, juntas, respondem por $82,7 \%$ e $73,4 \%$, a opção pelo turno da noite representa 4,7\% e 15,3\%. Faz-se necessário, entretanto, destacar que há um percentual considerável de estudantes de Pedagogia oriundos do noturno, o que marca uma diferença importante em relação ao grupo da Letras. Já, no que se refere ao ensino em tempo integral (manhã e tarde) - praticamente o mesmo nos dois grupos, $10 \%$ (Letras) e 9,3\% (Pedagogia), é provável que corresponda, em parte, aos 14,7\% (Letras) e 11,3\% (Pedagogia) que cursaram a modalidade Técnico. Destaque-se que, nos dois casos, o percentual de estudantes que cursaram à noite, 4,7\% (Letras) e 15,3\% (Pedagogia), ultrapassa bastante os percentuais relativos àqueles que cursaram a modalidade Supletivo: $2,6 \%$ e $6 \%$, respectivamente.

Quadro 6 - Mudança de colégio:

\begin{tabular}{l|c|c|c|c}
\hline \hline \multicolumn{1}{c|}{$\begin{array}{c}\text { Questão 6: Você mudou de colégio na última } \\
\text { série do ensino médio? }\end{array}$} & Letras & Pedagogia & \% \\
\hline Não & 120 & 80 & 137 & 91,3 \\
\hline Não Respondeu & 6 & 4 & 3 & 2 \\
\hline Sim, para uma escola mais conceituada & 10 & 6,7 & 2 & 1,3 \\
\hline Sim, por outras razões & 4 & 2,6 & 4 & 2,7 \\
\hline Sim, por razões de localização & 8 & 5,3 & 2 & 1,3 \\
\hline Sim, por razões de ordem financeira & 2 & 1,4 & 2 & 1,3 \\
\hline Total & $\mathbf{1 5 0}$ & $\mathbf{1 0 0 , 0}$ & $\mathbf{1 5 0}$ & $\mathbf{1 0 0}$ \\
\hline \hline
\end{tabular}


A quase totalidade dos estudantes de Pedagogia não mudou de escola: 91,3\%. O mesmo ocorreu com 80\% dos matriculados em Letras. A pergunta parece estar diretamente voltada para detectar a incidência de uma prática que se disseminou na cidade do Rio de Janeiro. Há uma oferta muito expressiva (e agressiva) de serviços de treinamento para os exames vestibulares por parte de instituições privadas. Não só parte da população acredita que cursar o ensino médio em uma instituição que ofereça serviços dessa ordem aumenta as chances de sucesso nos vestibulares, como também as próprias instituições, a fim de produzir bons índices de aprovação, recrutam nas escolas estudantes que se destacam, aos quais oferecem isenção total ou parcial de mensalidade para que cursem parte do ensino médio em suas turmas. O resultado apresentado mostra que provavelmente isso não ocorreu de forma significativa nos grupos que estamos estudando. Registre-se, todavia, que o percentual maior dentre os estudantes que mudaram ocorre no caso de Letras, com 6,7\% tendo afirmado que o motivo da mudança se relaciona com a busca de uma escola mais conceituada, o que talvez tenha alguma relação com o foco da questão.

Quadro 7 - Preparação em cursinhos:

\begin{tabular}{l|c|c|c|c}
\hline \hline Questão 7: Você frequentou "cursinho"? & Letras & $\mathbf{\%}$ & Pedagogia & $\mathbf{\%}$ \\
\hline Não & 80 & 53,3 & 68 & 45,3 \\
\hline Não Respondeu & 5 & 3,4 & 3 & 2 \\
\hline Sim, por mais de um ano & 10 & 6,7 & 9 & 6 \\
\hline Sim, por um ano & 38 & 25,3 & 36 & 24 \\
\hline Sim, por um semestre & 17 & 11,3 & 34 & 22,7 \\
\hline Total & & $\mathbf{1 0 0 , 0}$ & $\mathbf{1 5 0}$ & $\mathbf{1 0 0}$ \\
\hline \hline
\end{tabular}

Esta questão se conjuga com a anterior. Mais uma vez, a maioria, 53,3\% (Letras) e 58\% (Pedagogia), não frequentou cursinho. Entre os que frequentaram, $11,3 \%$ e $22,7 \%$, respectivamente, o fizeram por um semestre, indicando que a preparação específica em instituições ditas especializadas não se configura como uma estratégia adotada largamente nesses grupos. Há, todavia, um crescimento impressionante de cursos de pré-vestibular comunitários, muitos deles apoiados e desenvolvidos por universidades públicas (inclusive a UFRJ) e prefeituras diversas no Rio de Janeiro, o que não está contemplado nas opções de resposta na Questão 7. Considerando que as ações comunitárias se intensificaram no tipo de meio social de onde provém a maioria dos estudantes, é razoável supor que uma parcela tenha tido acesso a esse tipo de preparação.

Quadro 8 - Ano de conclusão do ensino médio:

\begin{tabular}{l|c|c|c|c}
\hline \hline \multicolumn{1}{c|}{$\begin{array}{c}\text { Ano de conclusão do curso de ensino } \\
\text { médio: }\end{array}$} & Letras & \% & Pedagogia & \% \\
\hline 2006 ou antes & 7 & 4,7 & 6 & 4 \\
\hline 2007 & 15 & 10 & 9 & 6 \\
\hline 2008 & 34 & 22,7 & 31 & 20,7 \\
\hline 2009 & 68 & 45,3 & 71 & 47,3 \\
\hline Não Respondeu & 26 & 17,3 & 33 & 22 \\
\hline Total & $\mathbf{1 5 0}$ & $\mathbf{1 0 0 , 0}$ & $\mathbf{1 5 0}$ & $\mathbf{1 0 0}$ \\
\hline \hline
\end{tabular}

Praticamente a metade dos respondentes, 45,3\% (Letras) 47,3\% (Pedagogia), concluiu o ensino médio no ano previsto: 2009. Somados aos que concluíram em um dos dois anos anteriores, perfazem $78 \%$ (Letras) e $74 \%$ (Pedagogia), indicando que a grande maioria se encontra dentro de um tempo razoável de conclusão da escolarização prevista. Chamamos atenção, contudo, para o alto índice de estudantes que não responderam $17,3 \%$ e $22 \%$ - bem acima do ocorrido com essa opção nas questões anteriores. Verificando o ano de nascimento dos que não responderam à questão, encontramos que 19 dos 26 de Letras e todos os 33 de Pedagogia nasceram em datas que são incompatíveis com a conclusão antes de 2006. Ou seja, praticamente todo o contingente dos que não responderam pode ser contabilizado na opção 2006 ou antes, elevando os percentuais da opção de 4,7\% para 17,3\% (Letras) e de 4\% para 26\% (Pedagogia). 


\section{ANÁLISE DOS DADOS}

Apresentados de maneira descritiva, os dados passam agora a ser tratados sob uma perspectiva mais analítica. Para tanto, buscamos um diálogo com dois estudos que tratam de perfis socioeconômicos de estudantes de licenciatura: um de Pereira (2006), que estuda o caso da UFMG, e outro de Gatti (2010), que usa dados do ENADE 2005. Preliminarmente, consideramos que os dados do presente estudo não apresentam nenhuma discrepância digna de registro em relação aos resultados dos trabalhos aqui referidos.

Retomando a apresentação, começamos pela questão do município de origem dos estudantes, que não tem relação com os dois estudos citados. Os percentuais indicam uma clara concentração de estudantes provenientes do Estado do Rio de Janeiro e, em especial, da sua capital. O restante dos estudantes vem, em sua maioria, de cidades a menos de $100 \mathrm{~km}$ do município do Rio de Janeiro, onde estão situadas as unidades da UFRJ responsáveis pelos respectivos cursos, a Faculdade de Educação e a de Letras. Não obstante essa concentração, tem crescido significativamente, nas últimas duas décadas, o número de problemas relacionados com deslocamento dos estudantes. Há muitas queixas deles em relação ao custo e ao tempo necessário para fazer frente ao cumprimento dos horários e ao retorno para suas residências, especialmente à noite.

A administração superior da UFRJ tem respondido a essas dificuldades com políticas de assistência estudantil, que, ao que tudo indica, não têm logrado resolver inteiramente os problemas. O resultado mais visível se mostra em índices abaixo do desejável no que tange à pontualidade, assiduidade e disponibilidade para atividades fora da rotina das aulas por parte dos estudantes.

Um segundo aspecto a destacar é o da faixa etária dos estudantes. Embora não apresentado nas tabelas anteriores, esse dado acabou por se revelar em função da análise à Questão 8, que trata do ano de conclusão do ensino médio. Diante do alto percentual de estudantes que não responderam à questão, recorremos às datas de nascimento para estabelecer alguma resposta. Como já afirmamos, praticamente todos os não respondentes concluíram seus cursos em 2006 ou antes, o que está de acordo com os achados de Gatti (2010, p. 1362):

É possível, porém, fazer uma distinção entre os estudantes de Pedagogia e os alunos das demais licenciaturas: os primeiros tendem a ser mais velhos. Enquanto apenas $35 \%$ dos alunos de Pedagogia estão na faixa ideal de idade para o curso, essa proporção aumenta para os estudantes das demais licenciaturas, sendo que entre os estudantes de Letras e da área de Humanas a proporção na faixa ideal está em torno de $45 \%$ (...) Os alunos de Pedagogia são também mais numerosos nas faixas etárias dos mais velhos, no intervalo de 30 a 39 anos, ou acima de 40 anos.

Os dados do nosso estudo corroboram os de Gatti (2010): considerando que a idade ideal seja até os 18 anos, encontramos $44,6 \%$ na Pedagogia e $55,3 \%$ na Letras. Apenas como referência de um curso de alto prestígio e alta procura na UFRJ, registramos que, no caso dos estudantes de Comunicação Social, esse percentual é de $72 \%$. Caso se amplie a idade ideal para até os 19 anos, os percentuais sobem, respectivamente, para 69,6\% (Letras), 74\% (Pedagogia) e 86,5\% (Comunicação Social). Na outra ponta da tabela, no grupo da Pedagogia, há 23 estudantes com mais de 30 anos (15,3\%); na Letras, há 12 (8\%) e na Comunicação Social, curso em que o estudantes mais velho tem 26 anos, não há nenhum.

Segundo Pereira (2006, p. 87), "A maior parte dos aprovados nos cursos de Licenciatura apresentou idade variando de 20 até mais de 30 anos”. Para o autor (2006, p.88):

Naqueles [cursos] com opções para a Licenciatura, de um modo geral, a maioria dos aprovados concentra-se em uma faixa etária maior do que a observada nos cursos mais e menos disputados da UFMG. É importante ressaltar o significado social da entrada do aluno mais velho na Universidade. Geralmente, o aluno que demorou a conseguir uma vaga em um curso de ensino superior, o fez por dificuldades socioeconômicas e/ou problemas na trajetória escolar. 
Admitindo-se que os dados referentes à idade têm forte relação com questões socioeconômicas, como afirma Pereira (2006), fica acentuada uma expressiva diferença entre os cursos aqui analisados e os de alta procura, assim como uma discreta vantagem dos estudantes de Letras em relação aos de Pedagogia. Para avançar mais nesse sentido, estamos finalizando a análise de dados dos demais grupos do questionário, especialmente os que dizem respeito a indicadores de poder aquisitivo (e.g. renda familiar, patrimônio, acesso a bens culturais). Isso não impede, contudo, que façamos alguns avanços por meio de cruzamentos dentro do próprio grupo de dados de escolarização.

Nesse sentido, Pereira (2006, p. 92) afirma que a tabela com os dados referentes ao tipo de escola em que os candidatos cursaram o ensino médio "evidencia a predominância de alunos egressos da rede particular". Ainda segundo o autor (p. 94); "Para egressos da rede pública de ensino, grande parte dos cursos de Licenciatura parece constituir via de acesso à Universidade". Também para Gatti (2010, p. 1364) "os estudantes provêm, em sua maioria, da escola pública”, com percentual ligeiramente superior entre os de Pedagogia.

As relações entre os fatores tipo de escola cursada, condição socioeconômica, qualidade da escolarização e condições para cursar o ensino superior estão marcadas por alta complexidade. Por esse motivo, há muitas ressalvas e cuidados a adotar na análise desse quesito.

A princípio trabalhamos com a premissa de que o conjunto das escolas públicas promove uma escolarização de qualidade sofrível. No caso do Rio de Janeiro, como em outros estados do Brasil, abre-se exceção para as escolas federais e os colégios de aplicação ligados a universidades públicas. Segundo estudo elaborado pela Comissão de Acesso do Conselho de Ensino de Graduação da UFRJ, dos candidatos aprovados para matrícula em 2010, 17,31\% vieram de escolas públicas federais (16), ao passo que somente 6,29\% eram oriundos de escolas públicas estaduais (76). Agrava-se o quadro quando se registra que cerca de $82 \%$ dos concluintes do ensino médio no Rio de Janeiro vêm de escolas públicas, em sua grande maioria, estaduais.

Embora a UFRJ não tenha se ocupado de produzir estudos acerca da origem específica de cada matriculado oriundo de escola pública, parece razoável sustentar que os estudantes das escolas federais e do Instituto de Aplicação da UERJ ingressam preferencialmente em cursos de maior prestígio e procura. Admitindo-se essa premissa, torna-se razoável também afirmar que os estudantes de Letras e de Pedagogia, que vêm em grandes proporções de escolas públicas $(45,4 \%$ e $61,3 \%)$, tenham cursado o ensino médio em estabelecimentos estaduais. Reforça essa hipótese o fato de que 31,6\% dos matriculados em Letras e 22,3\% dos ingressantes na Pedagogia tenham cursado a maior parte do seu ensino médio em municípios em que só há escolas públicas estaduais.

Para confirmar essa suposição, obtivemos junto à Comissão Executiva dos Concursos de Acesso aos Cursos de Graduação a relação de escolas em que os estudantes cursaram o ensino médio, o que nos permitiu chegar aos seguintes dados: dos estudantes de Letras, 2 cursaram o ensino médio no Colégio Militar, 11 no Colégio Pedro II, 6 em escolas técnicas estaduais e 1 no Colégio de Aplicação da UFRJ; no caso da Pedagogia, 1 veio do Colégio Militar, 7 vieram do Pedro II, 1 do Colégio Newton Braga e 1 de escola técnica estadual. Considerando as escolas destacadas como instituições públicas de maior qualidade, registram-se os totais de 20 estudantes de Letras e 10 de Pedagogia oriundos de tais instituições, o que representa, respectivamente, $29,4 \%$ e $10,8 \%$ do total dos que cursaram o ensino médio todo em escolas públicas. Esses percentuais ajudam a sustentar a afirmação de que a maioria - 70,6\% de Letras e 89,2\% de Pedagogia - vem de escolas estaduais regulares.

Com relação às escolas particulares, cumpre reforçar a afirmação anterior sobre a sua suposta qualidade. Responsável pela escolarização de cerca de $18 \%$ dos concluintes do ensino médio, a malha de escolas particulares do Estado do Rio de Janeiro - com expressiva concentração na capital - não pode ser classificada como um conjunto homogêneo. Trata-se de vários grupos de estabelecimentos, com investimentos pedagógicos diversos. Quando o senso comum se refere, de forma simplificadora e 
reducionista, à supremacia das escolas particulares, na verdade, isso tem por base um restrito grupo de escolas com tradição, projetos pedagógicos consistentes e corpo profissional qualificado. São instituições de custo elevado, que atendem às camadas com maior poder aquisitivo da população. Há, entretanto, uma proliferação de escolas de qualidade e custo menores que estabelece uma espécie de mercado mais acessível para as famílias que não se sentem contempladas pela rede estadual e não conseguem ingresso nas escolas federais. E esse segmento da malha particular tende a se ampliar, de modo a atender às camadas mais pobres da população, que julgam estar investindo, não sem sacrifício, em uma escolarização mais segura e melhor. Sem entrar na discussão acerca das políticas que reconfiguraram as escolas públicas em todos os níveis nos últimos 50 anos, considero apropriado marcar que, mesmo no juízo das classes com menor poder aquisitivo, as escolas estaduais no Rio de Janeiro passaram a ocupar um lugar para os desprovidos e, portanto, um lugar com menores condições de promover educação que leve à ascensão social. Nos termos de Algebaile (2009, p. 26):

Num país como o Brasil, onde a pobreza, não sendo residual nem transitória, é tratada permanentemente como se o fosse, e onde o nível de ensino mais elementar atravessa todo um século sem jamais completar sua saga de universalização, é válido pensar que escola pública e pobreza se fazem, a ponto de suas histórias resultarem, em boa parte, de um profundo e mútuo atravessamento.

As poucas aproximações que fizemos em relação ao ranqueamento das escolas na aprovação nos concursos de ingresso reforçam a percepção de que há um número reduzido de escolas públicas e privadas que atingem percentuais significativos. Os estudantes oriundos dessas escolas estão concentrados nos cursos de maior procura. Acerca disso, apenas para estabelecer algum termo de referência, recorro novamente ao estudo da Comissão de Acesso do CEG, no qual se observa que, em 2010, 52,4\% dos inscritos nos mais de 100 cursos de graduação que a UFRJ oferece pleiteavam vagas em apenas 7 desses $\operatorname{cursos}^{5}$ : Engenharia, Medicina, Direito, Comunicação Social, Administração, Psicologia e Engenharia Química. No caso da área de Ciências Humanas, na qual está a Pedagogia e parte da Licenciatura em Letras, o curso com maior procura Comunicação Social - teve $70 \%$ dos aprovados egressos de escolas particulares.

Em síntese, embora não se possa simplificar a relação entre o caráter público/privado e a qualidade da escolarização, dados e inferências nos levam a considerar que os matriculados em Letras e Pedagogia provêm majoritariamente de escolas públicas estaduais e instituições privadas de baixo ou médio investimento pedagógico.

Um terceiro aspecto dos dados de escolarização merece atenção especial. Trata-se do percentual de estudantes que cursaram o ensino médio na modalidade Magistério do Ensino Fundamental (Curso Normal).

No caso específico do Curso de Pedagogia, pode-se considerar que, durante algum tempo, desde a sua criação, ao final dos anos 1960, o perfil dos estudantes mesclava oriundos de ensino médio regular com formados em Curso Normal, alguns destes com atuação profissional no então ensino primário. Esse panorama se modificou a partir da falência do projeto original dos cursos de Pedagogia - formar especialistas - e a sua consequente substituição pela formação de professores, inclusive os da educação infantil e das primeiras séries do ensino fundamental. A ruptura com o projeto fundante, no caso da UFRJ, começou a ocorrer nos anos 1980 e culminou em 1993, com a adoção de um novo currículo. A partir de então, já se pode supor que houvesse entre os estudantes de Pedagogia uma quantidade menor de normalistas e de professores em efetivo exercício da docência.

Os anos 1990, todavia, trouxeram pelo menos duas novidades com forte potencial para afetar esse cenário. A primeira tem a ver com o avanço da oferta e da demanda por educação infantil, fenômeno que se mostrou mais evidente no âmbito das classes superiores e na iniciativa privada, mas que, ainda que precariamente,

\footnotetext{
${ }^{5}$ A lista está organizada em ordem decrescente de procura.
} 
teve uma importante extensão para as classes subalternas e a malha pública. Houve, portanto, a abertura de um novo nicho profissional, carente de regulamentação, é verdade, embora com potencial para atrair jovens em início de carreira: as creches. Isso pode ter de alguma maneira recolocado o Curso Normal como uma opção de primeira profissionalização para os futuros estudantes de Pedagogia.

A segunda novidade deriva da promulgação de uma nova Lei de Diretrizes e Bases da Educação Nacional: a Lei 9394, de 1996. Destacam-se do texto legal, para o nosso tema, o Artigo 21, que inclui a educação infantil dentro da educação básica, confirmando a tendência de valorização dessa etapa de formação, e o Artigo 62, que determina que a formação de docentes para a educação básica ocorrerá:

em curso de licenciatura, de graduação plena, em universidades e institutos superiores de educação, admitida, como formação mínima para o exercício na educação infantil e nas quatro primeiras séries do ensino fundamental, a oferecida em nível médio, na modalidade Normal. (grifo meu).

Por um lado, a lei valoriza a educação infantil, por outro - ao propor que, além das universidades, também os institutos superiores de educação (ISE), previstos pela mesma LDBEN 9394, em seu Artigo 63, possam formar professores -, desvaloriza os cursos Normais, admitindo-os como espaços de formação mínima para o magistério.

Seja como for, ao contrário do que aconteceu em outros estados, no Rio de Janeiro não houve nenhum movimento significativo de criação de ISEs, tendo sido mantidas em atividade diversas escolas que oferecem a modalidade Normal. Ainda assim, cabe investigar o que representa a opção, por parte de estudantes de Pedagogia, por um ensino médio que promove uma profissionalização que irão obter em nível superior. Entendemos que tal investigação depende de ações que ainda não empreendemos em nosso grupo, mas, no âmbito do presente estudo, tentamos uma aproximação entre esse dado da escolarização e dois outros dados de grupos diferentes: a idade e a resposta à Questão 24, que trata da ocupação profissional do estudante.

Consideramos, no caso da idade, os nascidos antes de 1989 como possíveis sujeitos com colocação no mercado de trabalho e em busca de um estágio superior de formação. Dos 67 estudantes que cursaram Normal (17 de Letras, 50 de Pedagogia), apenas 14 (4 de Letras e 10 de Pedagogia) preenchiam o critério da idade. Destes, 6 não trabalham; 4 trabalham e contribuem para o sustento da família; 2 trabalham, mas recebem ajuda financeira da família; 2 sustentam a família. Não há, pois, elementos suficientes para que se estabeleça uma relação quer com a maior idade, quer com o exercício profissional da docência, dentre os que cursaram o ensino médio na modalidade Normal.

Resta, então, supor que a escolha, pelo menos no caso dos que cursaram escolas públicas, possa ter a ver com fatores como localização, oferta de vagas/turnos, prestígio social da escola, este último ainda residualmente afetado pelo valor atribuído até o início dos anos 1980 às escolas públicas estaduais que ofereciam a modalidade Normal.

O mesmo, contudo, não se pode afirmar sobre o conjunto de instituições particulares que mantêm ensino médio Normal. Não têm necessariamente tradição digna de destaque e, como entes privados, cobram mensalidades. Apesar disso, 12 dos estudantes (5 de Letras e 7 de Pedagogia), o que representa 18\% do total, custearam seu ensino médio em escolas particulares na modalidade magistério do ensino fundamental, fato para o qual não oferecemos nenhuma tentativa de explicação para além da carência de opções no universo dos estudantes, o que também pode ajudar a esclarecer o surpreendente número de estudantes matriculados em Comunicação Social que cursaram o ensino médio na modalidade Normal: 15 (6,5\%).

Nos estudos com que escolhemos dialogar, a referência a esses dados só estão presentes no caso de Gatti (2010). De acordo com tabela apresentada pela autora (p. 1366), tendo como base o ENADE 2005, cursaram a modalidade Normal $41,8 \%$ dos estudantes de Pedagogia e $20 \%$ dos demais licenciados, números superiores aos nossos $33,3 \%$ e $11,3 \%$, respectivamente. 


\section{CONSIDERAÇÕES FINAIS}

Nossa primeira síntese relativa aos dados de escolarização dos estudantes de Letras e de Pedagogia aponta que:

1. Os estudantes dos dois grupos apresentam perfis semelhantes, sendo os de Letras menos distanciados dos indicadores próprios de estudantes de cursos de alto prestígio e maior procura.

2. Os estudantes vêm basicamente da cidade do Rio de Janeiro e de cidades da região metropolitana.

3. A idade média dos estudantes está acima da encontrada em cursos de alto prestígio, havendo presença significativa de estudantes que ingressam com idades acima dos 20 anos.

4. A maioria dos estudantes de Pedagogia fez o fundamental todo (44\%) ou a maior parte (10,7\%), bem como o médio todo (61,3\%) ou a maior parte (4\%) em escolas públicas.

5. A maioria dos estudantes de Letras fez o fundamental todo $(49,4 \%)$ ou a maior parte $(9,3 \%)$, bem como o médio todo $(44,7 \%)$ ou a maior parte $(6 \%)$ em escolas particulares.

6. Nos dois grupos, a maioria estudou de manhã e/ou de tarde. Mais uma vez, a opção pelo ensino médio noturno - que caracteriza maior distanciamento em relação ao perfil dos estudantes aprovados em cursos de alta procura - está presente de forma mais expressiva no caso da Pedagogia $(15,3 \%)$ do que no de Letras $(4,7 \%)$.

7. Entre os estudantes de Letras, $53.3 \%$ não frequentaram cursinho. No caso da Pedagogia, o percentual foi de $45,3 \%$.

8. Há uma expressiva quantidade de estudantes que cursaram o ensino médio na modalidade Magistério do Ensino Fundamental: 11,3\% (Letras) e 33,3\% (Pedagogia), dado que não mostrou correlação importante com fatores como idade e ocupação profissional.

Os dados coletados apontam para a necessidade de aprofundar estudos. Será necessário investigar mais detidamente o tipo de escola pública/particular cursada, para situar a escolarização dentro de uma visão mais detalhada. Será igualmente preciso investigar mais a fundo os motivos que determinaram a escola pelo ensino médio na modalidade Normal.

Não obstante o reconhecimento dos limites deste estudo, consideramos que ele poderá servir como ponto de partida para uma nova lógica de planejamento, execução e avaliação em nossas práticas pedagógicas e, especialmente, nas ações relativas ao acompanhamento do processo de implantação dos currículos nos dois cursos.

Além disso, os dados de escolarização, devidamente relacionados aos de outros grupos, podem ajudar a UFRJ a tomar decisões mais consistentes no que se refere à política de acesso e permanência de seus estudantes de graduação. Em nossa pesquisa anterior - A Prova de Redação no Vestibular da UFRJ: histórias e desdobramentos, identificamos que um dos elementos básicos da proposta anunciada nos anos 1980 - a valorização da escola pública - acabou desaparecendo do discurso oficial ao longo da história dos vestibulares isolados. Nos anos 2000, o tema voltou ao centro dos debates, agora ligado à adoção de cotas e à adesão ao ENEM e ao SISU. A despeito da vontade e da intenção embutidas nas decisões, assim como em 1987 - quando nos desvinculamos do vestibular unificado, a fim de adotar um sistema de acesso que favorecesse a todos os estudantes, mas não produzimos um estudo criterioso das condições da escola pública -, podemos estar novamente investindo em um caminho que talvez não nos leve aonde queremos. E, caso isso aconteça, em grande parte será porque, mais uma vez, dentre outros aspectos, ignoramos quem são nossos alunos.

No caso do nosso principal objeto - os saberes docentes para o ensino da escrita - de que forma a escolarização pode ter afetado o seu domínio por parte dos estudantes? Como as disputas por paradigmas e 
as novas tendências nos estudos de leitura e escrita que marcam o cenário do ensino de Língua Portuguesa nas décadas recentes interferiram na escolarização dos matriculados em Letras e Pedagogia?

Apenas para retomar um aspecto que já abordamos antes (CASTRO, 2010), reapresentamos dados dos estudantes relativos às notas obtidas no Concurso de Acesso em que foram aprovados.

Quadro 9 - Notas obtidas no Concurso de Acesso ${ }^{6}$ :

\begin{tabular}{l|l|l|l|l}
\hline Média & \multicolumn{1}{l}{ Letras } & Pedagogia & Grupo 5 & Geral \\
\hline $\begin{array}{l}\text { Língua } \\
\begin{array}{l}\text { Portuguesa } \\
\text { Literatura } \\
\text { Brasileira }\end{array}\end{array}$ & 4,9 & 3,4 & 4,7 & 4,6 \\
\hline Redação & & & & \\
\hline
\end{tabular}

A discreta diferença entre os dois grupos, evidenciada nos dados de escolarização, aumenta no caso das notas obtidas: enquanto os estudantes de Letras atingiram médias superiores às do seu grupo e à geral, os de Pedagogia ficaram abaixo em ambos os casos. De forma geral, são pouco significativas todas as diferenças, exceto no que diz respeito às médias de Língua Portuguesa e Literatura Brasileira dos estudantes de Pedagogia, que, além de ser baixa, está mais de 1,5 pontos abaixo da média geral e também da média do grupo 5 .

Preocupados com tais médias, investigamos o número de estudantes que obtiveram nota inferior a 5,0 nas referidas provas. Os resultados indicaram quantidades pouco expressivas, no caso da prova de Redação: 19 $(12,6 \%)$ de Letras e 15 (10\%) de Pedagogia, mas extremamente preocupantes quanto à prova de Língua Portuguesa e Literatura Brasileira: 80 (53,3\%) de Letras e 141 (94\%) de Pedagogia.

Diante desses números, levantamos também as notas obtidas no ENEM, do qual não utilizamos a nota de Redação, e os resultados das provas específicas dos estudantes: Geografia, História e Língua Estrangeira? No caso do ENEM, as médias na área de Códigos e Linguagens e suas Tecnologias figuram em penúltimo lugar no aproveitamento dos dois grupos. Quanto às provas específicas - e discursivas - os resultados também preocupam; os de Letras obtiveram médias 2,94; 3,01 e 4,54. Em Geografia, História e Língua Estrangeira, respectivamente; os de Pedagogia alcançaram 2,3; 2,2 e 3,3.

Trata-se de um quadro que requer nossa atenção e que dificilmente poderá ser superado por meio de medidas paliativas e/ou compensatórias, como aulas de reforço das disciplinas do ensino médio, medida que algumas unidades da UFRJ estão propondo no presente momento. A questão deve ser tratada não como uma espécie de desvio pontual ou acidente localizado no processo de escolarização dos estudantes, mas como resultado de mudanças complexas que os projetos de sociedade, de educação e de escola vêm sofrendo nos últimos 50 anos no Brasil.

As reconfigurações das escolas públicas e privadas; a tensão entre projetos de formação calcados em uma visão cidadã-emancipatória e os que defendem uma linha economicista-pragmática; as políticas de precarização do magistério; a tecnologização dos processos de ensino; a adesão brasileira ao modelo de capitalismo dependente e ao papel proposto para as nações periféricas: muitos são os aspectos de que se compõe o cenário dos cursos de formação de professores para o ensino da escrita. E nenhum deles deve ser desconsiderado, mesmo que, por agora, estejamos tratando de uma superfície, de uma aparência, de resultados medidos com todas as imperfeições inerentes a tais processos de aferição.

\footnotetext{
${ }^{6}$ Até o concurso a que se submeteram os estudantes aqui analisados, os candidatos os cursos estavam organizados por grupos. Letras e Pedagogia estavam no Grupo 5.

${ }^{7}$ De acordo com a lógica do nosso concurso de acesso, à época, cada grupo fazia três provas específicas, cujo grau de dificuldade era maior que as chamadas não específicas. Para o grupo 5, as específicas eram Geografia, História e Língua Estrangeira.
} 
O fato de admitirmos em cursos dos quais sairão habilitados para ensinar a escrever estudantes com traços evidentes de uma escolarização abaixo do previsto deveria significar que estamos não apenas cientes disto, mas preparados para lidar com déficits de ordens diversas. Estamos convencidos, porém, de que infelizmente, apesar de nossos esforços neste sentido, não estamos promovendo a superação de déficits básicos nem, por conseguinte, oferecendo aos estudantes condições adequadas de formação para o ensino da escrita para além de uma tímida reprodução de práticas e aplicação de materiais pedagógicos.

\section{REFERÊNCIAS}

ALGEBAILE, Eveline. Escola pública e pobreza no Brasil: a ampliação para menos. 1. ed. Lamparina; FAPERJ, 2009.

BARTHES, Roland. O grau zero da escrita. Porto, Edições 70, 1997.

BOURDIEU, Pierre. Esquisse d'une théorie de la pratique. Genebra: Droz, 1972.

BRASIL. Lei de Diretrizes e Bases da Educação Nacional: Lei 9394, de 20 de dezembro de 1996. 5. ed. Brasília: Câmara dos Deputados, Coordenação Edições Câmara, 2010.

BRITTO, Luiz P. L. A sombra do caos: ensino da língua x tradição gramatical. Campinas: Mercado das Letras; ALB, 1997.

CASTRO, Marcelo M. C. e. Por que escrever? Uma discussão sobre o ensino da produção textual. 2. ed. Rio de Janeiro: Edição do Autor, 2008.

Formação de docentes para o ensino da escrita: dados iniciais para um perfil dos estudantes de Pedagogia e de Letras (Português-Literaturas) da UFRJ. In: COLÓQUIO INTERNACIONAL SOBRE LETRAMENTO E CULTURA ESCRITA - diversidade e diferença na educação: cultura escrita, letramentos, políticas linguisticas e identidades. 3., Belo Horizonte, 5 a 8 de outubro de 2010. Anais... ISBN: 978-85-8007-014-9

Saberes docentes e formação de professores para o ensino da escrita: elementos para um projeto de formação inicial de professorers da UFRJ. In: SIMPÓSIO INTERNACIONAL DE ENSINO DE LÍNGUA PORTUGUESA, 1., Uberlândia, UFU, 2011. Anais... ISSN: 2237-8758.

GATTI, Bernadete A. Formação de professores no Brasil: características e problemas. Educação छ Sociedade: revista de Ciências da Educação, Centro de Estudos Educação e Sociedade - v. 31, n. 113, p.10751432, out-dez 2010.

GERALDI, João W. Portos de passagem. São Paulo, Martins Fontes, 1997.

KRAMER. Sonia. Escrita, experiência e formação - múltiplas possibilidades de criação de escrita. In: ENCONTRO NACIONAL DE DIDÁTICA E PRÁTICA DE ENSINO (ENDIPE) - Linguagem, espaços e tempos no ensinar e aprender. Anais... Rio de Janeiro: DP\&A, 2000.

LELIS, Isabel Alice. Do ensino de conteúdos aos saberes do professor: mudança de idioma pedagógico? Educação E̊ Sociedade, São Paulo, ano XXII, n. 74, 2001.

LESSARD, Claude; TARDIF, Maurice. As transformações atuais do ensino: três cenários possíveis na evolução da profissão de professor. In: LESSARD, Claude; TARDIF, Maurice. O ofício de professor: história, perspectivas e desafios internacionais. Petrópolis, RJ: Vozes, 2008.

LETA, Maria M. Relações de professores com a escrita. Rio de Janeiro: H.P. Comunicação, 2005.

NÓVOA, Antonio. Os professores e o "novo” espaço público da educação. In: LESSARD, Claude; TARDIF, Maurice. O oficio de professor: história, perspectivas e desafios internacionais. Petrópolis, RJ: Vozes, 2008.

PEREIRA, Júlio E. D. Formação de professores - pesquisa, representações e poder. 2.ed. Belo Horizonte, Autêntica, 2006.

PERRENOUD, Philippe. A prática reflexiva no ofício de professor: profissionalização e razão pedagógica. Porto Alegre: Artmed, 2002. 
PIMENTA, Selma G. Professor reflexivo: construindo uma crítica. In: PIMENTA, Selma G.; GHEDIN, Evandro (Orgs.). Professor reflexivo no Brasil: gênese crítica de um conceito. São Paulo, Cortez, 2008.

TARDIF, Maurice. Saberes docentes e formação profissional. 8. ed. Petrópolis: Vozes, 2007.

Recebido em 15/os/2011. Aprovado em 07/12/2011. 